\title{
Influence of Emergent Strategic Management Mode on Performance of Small and Medium Enterprises in Machakos Town, Kenya
}

\author{
Truphena Nyang'ara Osinde, Robert Arasa, and Jacinta Munyiva Kinyili
}

\begin{abstract}
The objective of the study was to investigate influence of emergent strategic management mode on performance (sales) of SMEs in Machakos Town, Machakos County. Descriptive research design was employed to ensure a complete description of the situation of SMEs performance in Machakos town. The target population was 16,399 licensed SMEs in Machakos Town. These SMEs where grouped into eight categories. Using stratified random sampling method, a sample of 390 respondents was selected from the target population. Data was collected using questionnaires design to obtain accurate information from respondents. Collected data was analyzed using both qualitative and quantitative techniques. Due to non-normality and non-homogeneity of the dependent variable, a non-parametric test (Mann-Whitney $U$ test) was preferred instead of a parametric test (t-test).Under this test, the data was categorized into low users of each strategy and high users of each strategy. The findings were presented using tables, figures, pie charts and graphs. The results indicated that SMEs which applies emergent strategy practices tend to have higher performance. Thus we conclude that emergent strategy practices positively influence performance of SMEs in Machakos Town. The study findings help SMEs strengthen their operations to ensure that the SMEs have a competitive edge to match their counterparts across other counties. The study recommends the need to have owners/managers of the small and medium enterprises undertake basic business and management skills training. Training the senior managers give opportunity to learn strategic management skills which will be valuable in their daily operations.
\end{abstract}

Index Terms-Influence, Emergent, mode, sales, performance.

\section{INTRODUCTION}

This study embarked on investigating influence of emergent mode of strategic management on small and medium enterprises (SMEs) in Machakos Town. Emergent mode of strategic management is described as unpredictable and often unintentional, it can come anywhere and involves relatively informal self-organised change.

Many ways have been adapted by SMEs to measure performance. This study has used sales as a measure of performance because most of SMEs record their annual sales that can be aggregated to annual sales.

In Kenya, there are 1.56 million licensed Small and

Published on October 11, 2019

T. N. Osinde is with the School of Business and Economics, Machakos University, Machakos, Kenya (e-mail: osindetruph@gmail.com).

R. Arasa is with the School of Business and Economics, Machakos University, Machakos, Kenya (e-mail: rarasa4@gmail.com).

J. M. Kinyili is with the School of Business and Economics, Machakos University, Machakos, Kenya (e-mail: jmunyiva001@gmail.com).
Medium enterprises (SMEs) and 5.85 unlicensed SMEs (Economic survey, 2017). This constitutes close to about 96 per cent of all business enterprises in the country (Economic Survey, 2009). SMEs represent the largest sector in the economy employing up to $75 \%$ Kenya's workforce and contributing up to $18.4 \%$ of the country's Gross Domestic Product (GDP) (Economic Survey, 2009). The SMEs in Kenya fall under the popular informal sector called Jua Kali. The name reflects the fact that they largely start in the open sun under no roof. It is indicative of the severe conditions under which micro-entrepreneurs and their employees labour (Kinyua, 2014). This sector comes into existence as result of the incapacity of formal and regulated industries to absorb new entrants. The SMEs encompasses small scale entrepreneurs and workers who lack access to enough credit, property rights, training, and good working conditions. Originally restricted to artisans, the term has come to include a number of professions, including auto mechanics and market vendors. The sector employed $83.1 \%$ of Kenyan workforce in 2016 and 89.7 percent of new job created in the same year were in SMEs sector (Economic survey 2017 )

SMEs which falls into informal sector are crucial for the economic prosperity, however, there are number of challenges that these SMEs face in the process of operations and performance. It is generally recognized that Small and Medium Enterprises SMEs face unique challenges, which affect their growth and profitability and hence, diminish their ability to contribute effectively to sustainable development to the economy. Despite the big role SMEs play in the economy past statistics indicate that three out of five businesses fail within the first few years of operation (Bunyasi et al, 2014). The reasons for the failure include limited market access, limited access to information, finances, technology, unfavourable policy from government and regulatory environment among others. There are various other challenges that have continued to have a negative impact on the growth of SMEs in Kenya. These challenges include, but may not be limited to, poor infrastructure, insecurity and high cost of energy, management skill, as they are disadvantaged to attract high skilled personnel (Klass et al 2002). Kenya's financial sector has expanded rapidly over the last decade and lending to businesses including small and medium size-with an ability to channel credit affordable and efficiently for sustained economic development. World Bank-FSD Kenya team found that still it is a challenge to development of SMEs (Donaldson, 2014).The total SME lending portfolio in December 2013 was estimated at KSh332 billion, representing $23.4 \%$ of the 
banks' total loan portfolios.

The importance of SMEs in contributing to job creation and output growth is now widely accepted in both developed and developing countries and then regarding SMEs as the backbone of the economy (Kenya Bureau of Statistics Report). The Growth of Small and Medium Enterprises (SMEs) is a major driver for economy in many countries in the world because SMEs contribute to employment growth at a higher rate than larger firms. In the EU economy about 99.8 per cent of the enterprises are SMEs employing 67 per cent of the European workforce and developing 57 percent of the value added (European Statistical Data Support, 2008).

\section{A. Statement of Problem}

There has been increasing consciousness since early 1970s that SMEs are important for economic growth and development, it is for this reason SMEs in Kenya were prioritized in vision 2030, as a key factor in development through industrialization and alleviation of poverty. According to economic survey 2017, 14.9\% Kenyans draw their livelihood directly and indirectly from SMEs. SMEs in Kenya employing up to $75 \%$ Kenya's workforce and contributing up to $18.4 \%$ of the country's Gross Domestic Product (GDP) (Economic Survey, 2009). The sector employed $83.1 \%$ of Kenyan workforce in 2016 and 89.7 percent of new job created in 2016 was in SMEs sector.

Kenya, through Sessional Paper Number 2 of 1992, deliberately and officially developed policies recognizing informal enterprise as more than a residual employer for the survival of poor households. Recently Kenyan government came up with a number of initiatives to improve the performance of the SMEs some of which are youth and women enterprise funds and 30 percent of government procurement to be awarded to youth who mostly run SMEs. Government of Kenya too encouraged banks through policies and regulations that banks to have credit products that suite SMEs needs and their ability. This has been asteady growth of SMEs in the region in terms of performance, up to $23.4 \%$ of the banks' total loan portfolios were taken by SMEs by the year 2013 .

However, SMEs face many challenges in the process of operations and performance, which affect their growth and profitability and hence diminish their ability to contribute effectively to sustainable development of an economy.

Despite the big role SMEs play in the economy past statistics indicate that three out of five businesses fail within the first few months of operation and barely live to grow to become fully established firms (Bunyasi et al, 2014). The reasons for the failure include limited market access, limited access to information, finances, technology, unfavorable policy from government, poor infrastructure, insecurity and high cost of energy, (Sakwa, 2010).

Thus despite the high rate of stagnation and failure of SMEs in the country no comprehensive study has probed the strategic management challenges faced by these SMEs and explored the response strategies that have been adopted by the SMEs to counter the challenges in the ever changing and turbulent business environment with a view of improving performance. Previous studies have indicated that there are still many entrepreneurs of SMEs still not informed of strategic management concept and does not show much interest to use since they think it can only be of gain for large entreprises. They persist on the old operational modes instead of doing strategic management for they have no idea what the bright future has in store for them(Minzberg 1987).On the other hand the business owners limit employees participation into the process of strategy making/structuring thus impede their creativity being used allowing only the top executive to set up strategic mission .Moreover the Small and Medium Enterprise are more flexible than larger firms but the limitations right from limited capital resources, lack of technological knowledge and lack of a formal strategic management as a result of which they lack patience and passion to find the most suitable way to support itself hence impede their economic growth.(Njoroge2013).

However these past studies most of them being case studies are limited in their generalization and more and more comprehensive study is needed, while these studies compare well with the current study, they focused on general problems without addressing the response strategic modes and practices in place to counter the challenges to have better performance. Therefore this study sought to find out the influence of the emergent mode of strategic management adopted by SMEs and determine the correlation between the adopted strategy and performance of SMEs in Machakos town.

\section{LITERATURE REVIEW}

\section{A. Resource Theory}

The resource-based view (RBV) emphasizes the firm's resources as the fundamental determinants of competitive advantage and performance. The cognitive resource theory is a leadership theory of industrial and organizational psychology. The theory focuses on the influence of the leader's intelligence and experience on his or her reaction to stress. The essence of the theory is that stress is the enemy of rationality, damaging leaders' ability to think logically and analytically. However, the leader's experience and intelligence can lessen the influence of stress on his (or her) actions: intelligence is the main factor in low-stress situations, while experience counts for more during highstress moments. The cognitive resources of a leader refer to their experience, intelligence, competence and task-relevant knowledge (Barney, 1991).

This study concentrated on modes of managements employed by managers of SMEs. If all firms in the market have the same stock of resources, no strategy is available to one firm that would not also be available to another firm in the market (Cool, Almeida Costa and Dierick, 2002).

\section{B. Contingency Theory}

Friedman(1970) describes the main ideas underlying contingency in a nutshell: Organizations are open systems that need careful management to satisfy and balance internal needs and to adapt to environmental circumstances. There is no one best way of organizing. The appropriate form depends on the kind of task or environment one is dealing with. Management must be concerned, above all else, with achieving alignments and good fits: Leader-member 
relationship - high if the leader is generally accepted and respected by followers. Degree of task structure high if the task is very structured. It can be concluded that there is 'no one best way' or approach in management or doing things, different situation calls for different approach to handle, manage, and solve the arising issue concerned. Management and organization is an 'Open system', which embrace anomalies or challenges every now and then, which requires 'adaptable' and 'situational' solution in order to overcome or solve the problem or issue concerned. Resource-based theory which stems from the principle that the source of firms competitive advantage lies in their internal resources, as opposed to their positioning in the external environment. That is rather than simply evaluating environmental opportunities and threats in conducting business, competitive advantage depends on the unique resources and capabilities that a firm possesses..

\section{Empirical Review}

Gathungu (2013) sought to investigate the effect of entrepreneurship on development of SMEs in Gathunguri District in Kenya. The study used exploratory research design. The study established that entrepreneurs were able to market their products within the district but not around the county, the study also revealed that entrepreneurs were able to do simple daily keeping of business transactions but were not able do complex financial statements. Nakola (2015) carried out a study focusing on the effect of strategic orientation on performance of small and medium enterprises in Nandi. The study was informed by resource view theory, the study adopted exploratory research design. The population of study comprised 2053 registered SMEs in Kapsarbet Town Kenya. Cluster sampling technique was used to select a sample size of 335 SMEs .Descriptive statistics which include frequency distribution, percentages, means and standard deviation was used to analyse data. Inferential statistics was also used to draw implications from the data with regard to the regression model.

Njeru(2015) took a study which sought to determine the strategic management practices adopted by the top one hundred SMEs in Kenya and influence of strategic management practices adopted on organization performance. The study used descriptive design, structured questionnaire was used to collect data, and the target respondents were the senior managers. Data was coded and analyzed results were represented in tables and figures. The study found that top one hundred SMEs had adopted strategic management practices relation to situational analysis, strategy formulation, implementation and evaluation. The SMEs had adopted participatory mechanisms in strategic management practices hence ensure success of strategic management practice. The study also found that adoption of strategic management practices influence organization performance. Njoroge (2015) investigated marketing strategies and performance of SMEs at Matuu Town in Machakos. The study used descriptive research design. The data was collected using a semistructured questionnaire. The data collected was analyzed using descriptive and inferential statistics using the statistical package for social science (SPSS) .To establish the relationship between the dependent variable and independent variable the classical linear regression model was used. The study established that customer relationship, marketing strategies and technology used have a positive insignificant influence on performance of SMEs in Matuu Town while innovative marketing strategies have a significant negative relationship with the performance of SMEs in Matuu Town. The study concluded that marketing strategies influence the performance of SMEs. Auka (2016) examined the effects of strategic planning on performance of SMEs in Nakuru. The study used correlational study survey design. The data was collected using structured questionnaire, data collected was both quantitative and qualitative .The effects of environmental analysis, organizational direction and strategy formulation on firm performance were tested using person correlation analysis while multiple regression analysis was used to test the combined effect of environmental analysis, organizational directional strategy formulation on performance of medium enterprises in Nakuru Town. The study indicated that strategic planning significantly influences organizational performance.

\section{ReSEARCH METHOdOLOGY}

\section{A. Research Design}

This research design adopted by this study is descriptive design. Descriptive research design is a scientific method, which entails observing and describing the behavior of a subject without influencing it in any way. A descriptive study is concerned with finding out the what, where and how of a phenomenon.

\section{B. Target Population}

The population of this study were the managers of 16,399 SMEs in Machakos Town. Each of these SMES had one manager, therefore the target population was16, 399 SME managers in Machakos town.

\section{Research Instruments}

The research instrument in this study was questionnaire. A questionnaire is a pre-formulated written set of questions to which the respondents record the answers usually within rather closely delineated alternatives. Since this study covers a large area, questionnaires were the appropriate instruments for the study.

\section{Data Analysis}

The responses were analyzed using descriptive statistical methods). Non-parametric test (Mann whitney test) was used to investigate whether SMEs performance was influenced by the use of strategy practices. The responses were also analyzed using descriptive statistical methods, such as frequencies and percentages where data was subjected to further statistical analysis procedures within the statistical package for social scientists(SPSS) The findings were presented using tables, figures, pie charts, graphs and prose form for easier interpretation from which conclusion and recommendation were made on the influence of emergent strategic management mode on performance of small and medium enterprises in Machakos town. 


\section{RESUlts AND Discussion}

\section{A. Emergent Strategy Mode and Performance}

$\mathrm{H}_{\mathrm{o}}$ : the mean performance of low and high application of emergent strategy mode are equal

$$
\mathrm{H}_{\mathrm{o}}: \alpha 1=\alpha 2
$$

$\mathrm{H}_{\mathrm{a}}$ : the mean performance of low and high application of emergent strategy mode are not equal

$$
\mathrm{H}_{\mathrm{a}}: \alpha 1 \neq \alpha 2
$$

Table 5.1 shows that performance mean ranking for low users of emergent strategy mode is nearly six times (28.5) of high users of emergent strategy mode (179.00). Meaning that the more SMEs apply emergent strategy mode, the more likely the performance of the firm will be enhanced.

\begin{tabular}{|l|r|r|r|r|}
\hline & ESM & N & \multicolumn{1}{c|}{$\begin{array}{c}\text { Tean } \\
\text { Rank }\end{array}$} & $\begin{array}{l}\text { Sum of } \\
\text { Ranks }\end{array}$ \\
\hline Average Change in & 1.00 & 56 & 28.50 & 1596.00 \\
Sales & 2.00 & 245 & 179.00 & 43855.00 \\
& Total & 301 & & \\
\hline
\end{tabular}

\section{B. Hypothesis Testing}

$\mathrm{P}$ value was used in hypothesis testing to help support or reject the null hypothesis. At 95\% level of confidence, an alpha level of 0.05 was set as the critical p-value for hypothesis testing. Therefore, $\mathrm{p}$ - values $\leq 0.05$ were considered too small for the results to be random (i.e. happened by chance). That is, less than $5 \%$ probability that the results could be completely random and not due to anything else. However, large p-values $(>0.05)$ meant the results have high $(>5 \%)$ probability of being completely random. Hence, for small p-value $(\leq 0.05)$, we reject the null hypothesis. Meaning there is strong evidence that the null hypothesis is invalid. On the other side, a large p-value $(>0.05)$ meant that the alternative hypothesis is weak, so we fail to reject the null hypothesis.

From Table 5.2 the p-value for Mann-Whitney tests statistics is $<0.05$. Thus, we reject the null hypothesis (Ho) that the mean performance of low and high application of emergent strategy mode are equal. We then conclude that there is sufficient evidence that mean performance difference between the low and high application of emergent strategy mode is statistically significant. Thus higher use of emergent strategy mode practices results in statistically significant positively influence on SME performance $(\mathrm{p}<0.05)$.

\begin{tabular}{|l|r|}
\hline & Average Change in Sales \\
\hline Mann-Whitney U & .000 \\
Wilcoxon W & 1596.000 \\
$Z$ & -11.918 \\
Asymp. Sig. (2-tailed) & .000 \\
Exact Sig. (2-tailed) & .000 \\
Exact Sig. (1-tailed) & .000 \\
Point Probability & .000 \\
\hline
\end{tabular}

a. Grouping Variable: EM

\section{Influence of Emergent Mode on Performance of SMEs in Machakos Town}

The study showed that emergent mode of strategic affects performance of SMEs in Machakos town .The data analysis showed a sufficient evidence that mean performance difference between the low and high application of emergent strategy mode is statistically significant(Table4.9).Thus higher use of emergent strategy mode practices results in statistically significant positive influence on SME performance $\mathrm{p}<0.05$. The study also indicated that emergent mode was the most widely embraced by SMEs in Machakos town. The emergent strategic management practices in their operations included ready to learn on activities, gather data during action, reflect on gathered data, and adjust course of action whenever need arises.

\section{CONCLUSION}

The study sought to determine the influence of emergent strategic management on performance. The study established that the SMEs performance in Machakos is affected by strategic management. The study established that emergent mode of strategic management had a positive impact on performance of SMEs in Machakos town. The SMEs which embraced emergent mode of management recorded increased profits.

\section{RECOMMENDATIONS}

From the research that was carried out it recommends that the SME managers should be encouraged to embrace emergent strategy in their management as it registered high sales. The also recommends that there is need to have owners/managers of the small and medium enterprises undertake basic business and management skills training. The training will offer opportunity to learn strategic management skills, so as to improve SMEs performance

There should also be attempt for SME entrepreneurs /managers to engage business experts to draw business plans, vision statement for their prospective businesses so as to guide them in day to day running of their business. 


\section{REFERENCES}

AukaD.O (2016)Effects of strategic planning on performance of small and medium sized enterprises in Nakuru Town.wwwImbrijournalcom.

Bunyasi, G. N., Bwisa, H., and Namusonge G. (2014).Effect of Access to Business Information on the Growth of Small and Medium Enterprises in Kenya.International Journal of Business and Social Science Vol. 5, No. 10(1); September 2014

Cool, Karel, Almeida Costa, Luis and Dierickx, Ingemar,(2002) Constructing Competitive Advantage in Pettigrew, Andrew, Thomas, Howard and Whittington, Richard (Eds), Handbook of Strategy and Management, Sage publications

Donaldson W.E. (2014). Quality, Productivity, and Competitive Position, MIT Center for Advanced Engineering, Cambridge Mass

European statistical data support (2008). Annual Growth Survey, 2008.

Economic survey (2009). Opinion of the European Economic and Social Committee on the Annual Growth Survey 2009

Friedman, M. 1970. The social responsibility of business is to increase its profits. New York Times Magazine, September 13: 32-33, 122-124.

Kinyua A.N (2014). Factors Affecting the Performance of Small and Medium Enterprises in the Jua Kali Sector In Nakuru Town, Kenya. IOSR Journal of Business and Management Volume 16, Issue 1. Ver. IV, PP 80-93

Klass, B., McClendon, J., and Gainey,T. (2002).Trust and the role of professional employer organizations: managing $\mathrm{HR}$ in small and medium enterprises. Journal of Managerial Issues, 14, 1: 31-48.

Kothari R. Research Methology. New Delphi: New Age International (P) Ltd. 2004

Mintzerg and Waters(1985),Strategic management journal vol.6, 257-272( 1985)

Mugenda, O. M. \& Mugenda, A. G. (2003). Research methods: Quantitative and qualitative Approaches. Nairobi: African Centre for Technology Studies.

Nakola(2015),Effect of strategic orientation on performance of small land medium enterprises. International journal of economics

Njeru.G K.(2015),Strategic Management Practices and performance of Small and Medium Enterprises

NjorogeP.M(2015),Marketing strategies and performance of small and medium enterprises.inMatuuTown.Machakos,Kenya. 